\title{
From the everyday to IR: In Defence of the Strategic Use of the R-word
}

Dr. Olivia Umurenwa Rutazibwa, Käte Hamburg Kolleg/Center for G lobal Cooperation Research, Duisburg // University of Portsmouth olivia.rutazibwa@port.ac.uk

\section{Introduction}

In 2012, J ohn M. Hobson published his brilliant and exciting book 'The Eurocentric Conception of World Politics' in which he metic ulously exposes the patema lism, Eurocentrism and racism in the thinking of the great scholars of the intemational since 1760.

The thinkers that feature in the book like Mill, Kant, his own ancestor Hobson, Spencer, Pearson, Lenin, Stoddard, Mackinder, Wilson, Cobden, Marx, but also the more contemporary Morgenthau, Carr, Keohane, Bull, Gramsci, Wallerstein, Cox, Cooper, Ikenbemy, Ka gan, Igna tieff, Fukuya ma, Huntington, Krazner, Held, Nussbaum, Wheeler, Finnemoore, Rawls, Vincent, Donnell and others, collectively indeed form what is generally considered the a utho rita tive canon on the Intemational. Their thinking continues to be passed on as such in most IR courses today, thus making J ohn's critic al historiography all the more relevant in the present.

The importance of the wealth on information and insight in Hobson's painsta kingly thorough work can hardly be overestimated, for mainstream and (postc olonial) c ritic al sc hola rship a like. It is nevertheless striking how Hobson limits his framing of racism to the scientific and biological; a move which allows him to conclude that racism is no longer an appropriate framework through which to understand the scholarship after 1945. With Hitler sawing death and destruction in Europe on these grounds before and during the Second World War, and given the outc ome of that war, the ideas around biologic ally superior and inferior races a re seen - not just by Hobson - to have lost all legitimacy as a scholarly ca tegoriza tion and ranking of human kind.

At the same time though, he does not necessarily claim that racism and following his definition - other forms of systema tic hiera rc hising, exc lusion and violence against particulargroups of people hascome to an end in everyday life. But, in line with the perceived delegitimation of scientific racism a fter 1945, Hobson opts for labelling the continued expressions of superionity and varied ensuing practices and thought in intemational relations as Euroc entrism. Given that Hobson does not deny that the societal proc esses of prejudic es mixed with disproportionate (structural) power, continue to systema tic a lly cause disc rimination, violence and death to groups of people 
on the basis of certa in of their qua lities considered inferior or und esirable, thus opera ting a long similar lines and logic s of scientific racism -, a re still a live and well, it is all the more remarkable that he then dismisses it as a valid analytic al category for the post 1945 present.

It is the contention of this essay that, precisely given the daily, structural racism that unmistakably continues to plague our societies - people literally encountering death, destruction and discrimination they would not had they been 'white' - it is both a nalytic ally and nomatively near impossible to be at peace with the premature declaration of the end of scientific/biological racism as a prism through which to understand contemporary knowledge production on the (inter)national.

The question at hand in this commentary is not whether Eurocentrism in its va red manifestations as metic ulously developed in Hobson's book is not a valid and insightful a nalytic al category to understand the contemporary scholarship and world, because it is. What is at stake here is how this Eurocentrism relates to the category of racism and what the consequences are when the two are presented as separate rather than one (Eurocentrism) as one of the manifestations of the other (racism).

A first question that a rises from J ohn Hobson's a nalytic al choice in the context of continued racist (scientific and other) ${ }^{1}$ practices and thoughts in the everyday is: How can it be that academia would be miraculously cured from a sic kness that continues to befall J ohn, J ane, Mamadou and Mariam Doe on a daily basis? In other words, if racism, even in Hobsons narrow scientific (related to eugenic sand Darwinism) understanding of it, continues to systema tic ally feature in everyday life, can it be that this oc curs in the absence of a base for it in our contemporary sc holarship?

Secondly - given that Hobson is most certa inly not a lone wolf in his reluctance to deploy the racism label, or the R-word, in the present - which struc tural knowledge production pattemscan be discemed in the contemporary debate that allow for the R-word to be so contentious or almost compulsively written out of the na rative or a nalysis and what existing power structure does this reluctance serve?

This commentary will foc us mostly on the second question. With regard to the first one, it can overall be considered as a call for the revalorisation of the everyday in our reflexions on scholarship as well as a nalytic al choic es, rather

\footnotetext{
${ }^{1}$ Even though providing a precise definition of what racism is or is not, is not the a im here the foc us is rather on the nomative implications of strategic definitional choices in the use or not of the racism label - broadly speaking, I understand racism as the societal processes, including systems of thought, of prejudices mixed with disp roportionate (struc tural) power, that systematically cause discrimination, violence and death to groups of people on the ba sis of c erta in of their qua lities considered inferior or undesirable. In it in this sense that I would consider Euroc entrism a manifestation of racism.
} 
than that it will present a irtight pro of of the continued existence of racism in soc iety or scholarship. Mostly because I do not think that this is the disc ussion to be had with Hobson's invaluable work, as it does not necessarily contest such fact, not in the least because its ethos is funda mentally anti-rac ist.

With regard to the second question on the power of the reluctance to use the R-word - essentially a meta-question - the commentary seeks to develop some answers by shedding a decolonial light on both everyday life and scholarly knowledge production practices in an attempt to transcend the individual bias in the R-debate and revalorise the historical and structural stakes at hand in that conversation.

Dec olonia lity as a research option or stra tegy, put forward among others by the likes of Walter Mignolo, Rolando Vázquez, Maria Lugones, Nelson Maldonado-Torres, Ramón Grosfoguel and developed and applied in IR by scholars like Robbie Shilliam, Meera Sabaratnam, Julia Suárez-Krabbe, Branwen Gruffyd J ones (this list is by no means exha ustive) can be - very c rudely - summarised in a triple call of de-mythologising, de-silencing and anti-colonially de-colonising our knowledge production or cultivation practices.

Concretely and in this context, these strategies - presented separately for a nalytic al purposes but in practice very much interlinked - address the following questions: Blind spots: What part of the story is systematic ally left out? How are connec ted histories invariably fra gmented or distorted? (demythology) Whose stories and experiences a re systema tic ally ignored, muted, not heard, delegitimised? In other words, who does not get the mic rophone, is not a round the expert table, and why? (de-silencing) Finally, why does any of this matter, i.e. what is their relation to the colonial status quo, i.e. both their political and material signific ance, and how to alter this? (de-colonising)

So, in line with the concems expressed in the second question, rather than a debate over facts in J ohn Hobson's seminal work on scientific racism and Euroc entric institutiona lism, this essay is an explic itly nomative conversation and engagement with today's anything but new or isolated reluctance to use racism as a lens to understand the post-1945 world. The aim here is to draw attention to the fact that a nalytic al categones, a part from imperfect attempts to render rea lity intelligible, are a deeply noma tive enterprise that implic itly or explic itly seek to render (parts of) rea lity for a certa in purpose. Under scrutiny here is the extent to which R-word reluctance (dis)serves an anti-rac ist decolonial purpose.

Building on a vignette of the yearly racism-related debate around the figure of Zwarte Piet or Black Pete in contemporary Flanders, Belgium, this contribution fundamentally questions the salience of avoiding the use of the R-word in public debates and IR a like for strategic reasons and casts a light 
on how it operates in maintaining a colonial status quo, and if and to what extent J ohn Hobson's a nalytic al choic es unwilling ly are a part of this.

It is important to note that a strategic reluctance, as showcased by J ohn Hobson, distinguishes itself in fundamental ways from others' fundamental reluctance. The lattera) do not necessa rily promote an anti-racist ethos and/or b) question the mere existence of racism in the contemporary world as such. J ohn Hobson's work is not that.

In a way I challenge his, what I call here strategic, reluctance precisely because I see it in stark contrast with the deeply critical and anti-rac ist ethos at the heart of his work. Strategic reluctance in this sense is characterised by a desire to a void ascribing delegitimised intentions, like racism, to individuals when they did not have them. The prionity in such reflections is not to offend or a lienate certa in partic ipants from the conversation on struc tural injustice that is nevertheless seen to be crucial to have. Analytic ally limiting the hated R-category to scientific or biological racism only, is one concrete manifestation of this strategic reluctance.

\section{Vignette: innocence and racism in the Zwarte Piet tradition}

Every year, a round December $5^{\text {th }}$ and $6^{\text {th }}$ the Santa Claus-like figure Sa int Nicolas, sa ils into the ports of Netherlands and Flanders from Spa in to bring toys and sweets to the children.

In this Low Lands traditional, Saint Nic olas is accompanied by the figure of Zwarte Piet or Black Pete. This character is embodied by a small a my of black-faced individuals sporting a renaissance outfit from the times Spa in ruled over the region, with typical a fro-wigs, fea thered hats, red lipstick and hoop ea mings.

Zwarte Piet's role is twofold: he - in true slave narra tive style of the time - firstly func tions as Sa int Nic olas' help, camying the bags with toys and distributing sweets to the kids. His second role, very much in line with the tried bogey-man trope set aside for men of Afric an descent, is to scare children into good behaviour throughout the year. The story - passed on generationally through the many Sa int Nic olas child ren songs - goes that Black Pete will throw the bad kids in his empty bag and/or beat them with a rod.

In recent decades he has been more benignly rebranded in the other telltale trope of the silly, jokey, broadly smiling black minstrel whose role it is to make children laugh.

Until recently, every child in the Netherlands and Flanders grew up with this tradition, without them or their pa rents linking it to a nything remotely to do with racism. Not even I, a second generation Rwandan, black, Flemish kid growing up in Antwerp. Even the fact that I, when it was our tum in the last year of high school to dress up like Black Pete for the primary school kids, did not need to blacken my face, or that as a n adult, every year a round 
December, my sister and I would have small child ren fea rfully look at us in the street, did not stop me from embracing the collective Flemish innocence around this Zwarte Piet and Sinterklaas tradition.

Today we see this innocence being challenged. Less than five years ago a handful of people in Flanders, taking queue from activists in the Netherlands, started to point at the racist elements contained in this tradition and call for a ban or modification of the practice. This has stired a yearly, inva riably bitter yet still relatively marginal public conversation on racism in local traditions.

This Flemish attempt at a debate around the place of the figure of Black Pete in present-day Belgium and the Netherlands invariably showcases a set of biases, recurrent in most R-word debates, that illuminate the three decolonial points this commentary seeks to make on the reluctance to use racism as an analytic al category: 1) the ind ividualised bias of innocence and intentionality and intensity, 2) the bias of expertise and legitimacy, 3) the bias of the emotional and anecdotal at the expense of the structural. In what follows, the a im in is to scrutinise the different ways in which also strategic reluctance, as conta ined in Hobson's analytic al choices, unwillingly ends up reproducing simila $r$ biases or not.

\section{One: | De-mythology| The individualised bias of innocence, intentionality and intensity}

'How can a children's tra dition be racist?'

'It was not meant to be racist - hence it is not racism.'

These utterances, and the unspoken feeling that 'if it doesn't look like something Hitler would have done, it's not racism', a re some of the most recurrent objections when people have attempted to label something as racist. The Black Pete tradition context is just an example in which the element of innocence is partic ularly explic it.

In every-day life, an innocent children's tradition like Black Pete can never be racist. First of all, because of the clearly benign intentions of those that celebrate the tradition; secondly because of the fact that the potential representational ham done to people of African descent in such context is deemed incomparable to the horrors of the quintessential trope of racism all of us in the industrialised West grew up with: the Hitlerian moment.

The Hitlerian connotation attached to the racism label reduces it not only to a matter of good versus bad intentions, it also individualises a problem that is essentially a structural problem that opera tes at times through individual behaviour and powerful struc tures a like.

What, then, is the connection with the need to demythologise our knowledge production practices? In the context of a society that clearly bears the marks 
of continued systematic exclusion and violence aga inst people based on their appearance or affiliation, the only way these bia ses of ind ividuality, innocence, intention and intensity continue to make sense to people, is through a knowledge production system, and hegemonic historiography in partic ular, that susta ins partial, fragmented and distorted understanding of how, where and to what end racism operates. In Westem Europe we have reduced it to the acts of evil, probably lunatic, men - Hitler on top - but most importantly, they a re considered exceptional aberrations.

It is in this mythological c ontext of ind ividual responsibility, malevolence or innocence, and the disconnection between representational rac ist violence and mass a trocities that la belling contemporary a ctions, disc ourses or lines of thought a s rac ist, is often seen as an imped iment to construc tive dialogue. A systematic individualised approach to racism through the figure of 'the evil racist', leaves us with an incapacity to have an open and constructive engagement with this system of, by definition, ra cialised coloniality, i.e. a matrix of power that allows for the nomalisation and perpetuation extreme power inequalities, allowing for systematic dispossession, violence and even death of racialised peoples.

Whereas first and foremost features of the fundamental reluctance, the ind ividuality, innocence and intentionality tropes a re also embraced in strategic reluctance considerations when the use of the R-word is linked to the fear of hurting certa in people's feelings or an impediment to a structural conversation. It is on this basis that the strateg ic reluctant, like J ohn Hobson², is unc omforta ble to use the category of racism as an a nalytical tool to study the works of contemporaries like Keohane as to not to offend them.

In his book, J ohn Hobson showc a ses his a nti-colonial or -rac ist commitment by opting for the term Eurocentric institutionalism to pinpoint in more detail what is going on in post 1945 scholarship. The point is not that this is a wrong descriptor, because it is not. What is more, there is true value in the sophistic a ted and detailed study of this Eurocentric institutionalism and I will surely use this a nalytical tool in my own work and teaching.

The question at hand in the reluctant R-word debate is how this Eurocentrism is related to racism. Why is it presented as a different category all together rather than ma ybe a ma nifestation of racism, partic ular to the post 1945 era?

\footnotetext{
2J ohn's first concem, especia lly in his book, is of a nalytic al nature, a s he seeks to create the necessary space in which Eurocentrism can be clearly seen and disc ussed, something that, according to him, the blanket racism label does not allow us to do. An additional concem though, permeating his interventions (during debates and roundtables, or e.g. on the The Disorder of Things blog forum on his book (https://thedisorderofthings.c om/2012/10/23/eurocentrism-racism-whats-in-a-word-aresponse-to-bowden-sabaratnam-and-vucetic/) ), is how the people - dead or alive featuring in his work, would view the racist label being cast on their thinking, and take offence.
} 
If this strategic reluctance contributes to a perpetuation of the fundamental reluctants' distorted image of what racism is actually about, where does that leave our anti-rac ist sc holarly ethos? Is it not important to further doc ument and end lessly repeat that more than individual malevolence or lunacy, racism is the oil in the system of colonial power that makes a susta ined discrimination of and violence aga inst certa in people not only possible but also invisible and acceptable? At the same time, when we speak of hurt feelings and intentionality, whose feelings are we systematic ally valuing more than others' in our strategic reluctance? How does this play into the colonial status quo and the expendability of certa in experiences and lives?

This question brings us two the second leg of this decolonial commentary on the R-debate: that of the need to more systematic ally consider issues of silencing.

\section{Two: | De-silence| the bias of expertise}

Who are the experts?

Even though the initial contestation around the Black Pete figure was la unched by groups and individuals from the affected visible minority communities, the experts invited for a seat at the table in the Flemish Zwarte Piet disc ussion tend to invariably be members of the white male majority: historians, sc holars in ethic sor politic al representa tives of 'the people'. These unlikely experts on racism are then the solely trusted agents to define what constitutes as racism and what not. Their dia gnosis is too often that it is not racism because it was not intended as such, or the selected historical evidence of the tradition does not support such claims.

When visible minorities do make it a round the table, it is to either talk back to these objections or to a nec dotally expand on the emotional pa in Zwarte Piet might cause them and their community. Even when this invitation to share the personal pain comes from a genuine place of interest and care, this partic ula r type of interest or attempt at solida nity, unwillingly disqualifies them from being considered capable of objective overarching insights - still the key features of ourconception of what good knowledge and expertise is all about.

When we try to a void offending people in the R-word conversation by a voiding using the label - it bears the question of how we value the life and sentiments of those people systematic ally on the receiving end of the racism - or, if you like, Euroc entric institutiona lism. What makes it so acceptable that their experiences, intentions, feelings and suffering a re always subord inate to that of those that occupy positions of privilege in the colonial racist matrix of power? 
It is, among others, the systematic absence of the affected people around the expert-table of the R-word debate that makes 'offending' them or hurting their feelings more acceptable than the white majority and the experts it produces.

An additional hurdle, specific to our scholarly engagements with the racism conversation, is that racism as a phenomenon is implic itly or explic itly not felt to be objective or a nalytical enough. And so, we bend over backwards to come up with other, more neutral and measurable concepts: inequality, disc rimination, body/bio-politic s, ethnoc entrism, patema lism, imperialism, xenophobia, ignorance, ... without nec essa rily considering to whom such move might be offensive.

Can we not discem a similar bias in Hobson's work when there is more concem with offending contemporary scholarship by using the R-word as an analytic al category than with the very limited engagement with minority scholars throughout the book? We can hardly blame Hobson for the absence of a thorough engagement with a ltemative thinkers in the time frame under consideration, as it was clearly beyond the scope of this work that seeks to take the existing canon to ta sk. It is nevertheless important to raise this issue if we seek to further anti-rac ist IR sc holarship. We will fall short if we stop at merely denouncing what the mainstream scholars have been doing without digging up, fomenting altemative archives and elevating them to the level of the canonical, or, better yet, getting rid of the canonic al thinking all together.

It is only then, ac ademic ally speaking, that offending a Keohane or Spivak will camy the same weight, but more importantly, that it will stop being the basis on which we choose to use the racism label or not. Rather than worying about how it will be perceived by certain people, it will be the continued circ umstances of coloniality and structural racism in the everyday that will be the guiding principle in how to a nalytically orga nise our study of the social and the intemational.

\section{Three: | De-colonise| the bias of the individual over the historic al/ structural}

What is all the fuss a bout?

Another previously mentioned recuming objection put forward by the fundamental-reluctants in the Zwarte Piet R-word debate, is the fact that the issue is not serious enough to merit so much attention. This is due to the fact that the problem is identified as one of emotions and hurt feelings about things that happened in the past, cf. slavery. The hurt is therefore seen as something that can easily be overcome if one takes into account the lack of intentionality to cause pa in in the present. Again, as mentioned before, these reflections are made possible through a distorted, fragmented presentation of past wrongs and their presumed irrelevance in the present. With slavery, 
racism and colonialism being formally delegitimised in the present, our mythologic al knowledge production system susta ins the belief that the practic es have then also disappeared from the present everyday. Rarely, in the Zwarte Piet debate, is the connection made with the nature of Belgium's continued engagement with its former colonies, or with the living conditions of people of African descent in Flanders: their struc turally limited access to the labour, education and housing markets, their absence in representational positions of powercf. the media, teaching and politics; their overrepresentation in incarceration and poverty statistics.

It is important to reiterate that J ohn Hobson's work does not showcase the same bias. His pa insta king ly metic ulous historiogra phy of the scholarship on the intemational since 1760 up until 1945 most convinc ingly testifies to this. The question at this point then is: why is it so important that he does away with racism as an a nalytic al category to understand the post 1945 sc holarship if he clearly showcases a solid anti-colonial and anti-rac ist ethos throughout?

The contention, of nomative-stra tegic, rather than desc riptive-a nalytic al nature, of this commentary is that this is important, precisely because of the power of the Hitlerian moment - however distortedly (e.g. its exceptionality and individualised malevolence) this continues to be narrated to the masses. It is because of the presumed consensus a round the unacceptability of categorising and hierarchizing peoples along racial lines, that failing to orga nise our a nalytic al categories to understand structural injustic es in the present, is a seriously missed opportunity in the present. This is where the ultima te legitimacy of the invocation of the label of racism lies. Not as a blanket accusation or obfusc a ting category that does not allow us to study the partic ularities of the different manifestations of these struc tural forms of exclusion and violence on certain groups of people (hence my genuine excitement about J ohn Hobson's development of the Eurocentrism category and its different manifestations), but as a form of violence that has indeed been delegitimised in the Westem world after the Hitlerian moment. I believe that this is an advantage that from a norma tive standpoint, i.c. an anti-racist, anti-colonial ethos, should be embraced more seriously and systema tic ally in our sc holarly endea vours as well.

In this reflection I have tried to fundamental question the tendency to make the R-debate about individual and group emotions, whether these are of the whitened masculinised majority or the visible minorities - it is a bout so much more than that; the legitimacy of its unabashed invocation lies precisely in the fact that it is about struc tural well-being and justice for the whole of society, something that can only be done by systematic ally taking the past and the past in the present seriously.

Ultimately, if we are to focus on emotions (the day that the emotions of all a re considered a legitimate source of knowledge on parwith ratio I would be the first to do so) and hurt feelings in this deba te, it is important to start 
acknowledging that we have been prionitising the emotions and hurt feeling of the wrong group of people if we are truly concemed with the colonial matrix of power.

\section{Conclusion}

Hobson, and other strategic -reluctants within and outside academia, choose to a void the term racism or restrict it to its scientific/biologic al meaning, to keep the doorfordialogue open. The racism label being equated (both it its deployment and reception) to a personal charge - an insult to be avoided in a constructive dialogue -, prionity is given to the importance of a nalytical accuracy, as to not put all manifestations of struc tural injustice on the same R-word pile. These considerations perta in strategy, frameworks and choic es we make in how we want to label reality, render it intelligible and maybe try to change it.

The same goes for people like myself and others with me, who call for the explic it use of the term racism, both within and outside the scholarship. We maybe see racism as a main category with different ma nifestations. The systematic exclusion of and violence against people is not restric ted to the biological, yet its effects tend to be as devastating or unwanted; because we still live it on a daily basis and it somehow seems impossible to think it a way or beyond it - even when denied; because (individual) bad intentions do not expla in the (persistence of) the phenomenon and it seems that a structural, collective vision of it would do a better job at describing this experienced reality. As most contemporaries, thanks to the Hitlerian moment, agree that racism is something bad invoking the label could in theory save us a lot a time, which we could use to focus straight away on strategies to fight it. In our scholarly thinking. In the polic ies that orga nise our everyday.

Equally important though, is the rea lisation that neither of these positions is an objective rendering of reality.

Invoking decoloniality in this meta debate on the R-word has served to fimly break with the myth of a) a binary division between the everyday and scholarship when it comes to understanding the susta ined hierarchisation of peoples; b) scientific/biological racism that has been delegitimised beyond our disc ourses - if at all and c) racism being a bout a-historic al ind ividual Hitlerian malevolence.

Secondly, it has sought to highlight the need to put the experiences and contributions of historic ally ma rginalised minorities, e.g. the perspectives of people and scholarship of colour, beyond the emotional testimonials, at the centre of such choic es if we are to contribute to a radic ally different, anti- or non-racist IR and everyday. This desire is clearly reflected in Hobson's work, yet in the absence of - for understandable rea sons in this case - a sustained engagement with minority authors combined with his concem to offend 
contemporary colleagues, his strategic reluctance to use the R-word unwillingly hampers the third decolonial concem of anti-colonial decoloniality that seeks both in scholarship and practice to contribute to a radic al break with the colonial matrix of power of which struc tural racism, perpetuated among others in canonic al scholarship, is a fundamental feature.

Rather than seeking to proof that some of the post-1945 scholars featuring in Hobson's book are racist or not, the aim in this commentary has been to weigh in on the content and teleology of the R-debate. The contention is that our choic es of a nalytic al c a tegories, more than attempts to mea ningfully desc ribe rea lity, a re/should be embraced as deeply nomative enterp rises as well, more or less consc iously orga nising that rea lity for a certain purpose.

The a im has been to break with the idea that a nalytic al c ategories are merely attempts to capture an 'objective' reality out there; or can be reduced to peoples' conscious intentions. Apart from systematic devices to understand reality, they a re also understood as politic al or ideologic al choic es on why we seek to understand which part of reality. Informed by a decolonial approach, which highlights the need for demythologised, de-silenced and anti-colonially de-colonised knowledge production in the present, the essay has sought to argue that a strategic use of the R-word has an important role to play, as both a critical and analytic al devise in the study of IR. 